\title{
Occurrence, oral exposure and risk assessment of volatile organic compounds in drinking water for İzmir
}

\author{
Pinar Kaucar ${ }^{a}$, Mustafa Odabasi ${ }^{b}$, Mehmet Kitis $^{c}$, Fikret Inal $^{d}$, Sait C. Sofuoglu ${ }^{d, *}$ \\ ${ }^{a}$ İzmir Institute of Technology, Environmental Engineering MSc Program, Gulbahce, Urla 35430 İzmir, Turkey \\ ${ }^{\mathrm{b}}$ Department of Environmental Engineering, Dokuz Eylul University, Kaynaklar 35160 İzmir, Turkey \\ ${ }^{\mathrm{c} D e p a r t m e n t ~ o f ~ E n v i r o n m e n t a l ~ E n g i n e e r i n g, ~ S u l e y m a n ~ D e m i r e l ~ U n i v e r s i t y, ~ C u n u r ~} 32260$ Isparta, Turkey \\ ${ }^{\mathrm{d}}$ Izmir Institute of Technology, Department of Chemical Engineering, Gulbahce, Urla 35430 İzmir, Turkey
}

\section{A R T I C L E I N F O}

Article history:

Received 31 October 2005

Received in revised form

23 June 2006

Accepted 3 July 2006

Available online 22 August 2006

Keywords:

Volatile organic compounds

Drinking water

Exposure

Risk

Trihalomethanes

İzmir

\begin{abstract}
A B S T R A C T
Concentrations of volatile organic compounds (VOCs) were measured in the drinking water in Province of Izmir, Turkey, and associated health risks due to ingestion of these compounds were investigated using population weighted random samples. A total of 100 houses were visited in different districts of İmir and drinking water samples were collected from consumers' drinking water source. Questionnaires were administered to one participant in each house to determine demographics and drinking water consumption rates. Oral exposure and risks were estimated for each participant and İzmir population by deterministic and probabilistic approaches, respectively. The four trihalomethane (THM) species (i.e., chloroform, bromodichloromethane, dibromochloromethane, and bromoform), benzene, toluene, $p$-xylene, and naphthalene were the most frequently detected VOCs with concentrations ranging from below detection limit to $35 \mu \mathrm{g} / \mathrm{l}$. The risk estimates were found to be less than the values reported in the literature with few exceptions. Noncarcinogenic risks attributable to ingestion of VOCs for İzmir population were negligible, whereas the mean carcinogenic risk estimates for bromodichloromethane and dibromochloromethane were above the de minimis level of one in a million $\left(10^{-6}\right)$. For all VOCs, the concentrations measured in metropolitan area were greater than those in other districts. All THM species were detected in higher concentrations in tap water, whereas nontap water contained more benzene, toluene, $p$-xylene, and naphthalene. Therefore, the concentrations of the latter four compounds and associated risks increased with increasing income and education level since bottled water was used in larger proportions within these subgroups. The results of this study showed that oral exposure to drinking water contaminants and associated risks may be higher than the acceptable levels even if the concentrations fall below the standards.
\end{abstract}

(c) 2006 Elsevier Ltd. All rights reserved.

\section{Introduction}

Ingestion of drinking water containing volatile organic compounds (VOCs) may lead to liver and kidney damage, immune system, nervous system, and reproductive system disorders as well as several types of cancers (Cantor, 1997; Calderon, 2000; Fawell, 2000). VOCs are released into the environment during their production, storage and use, and can enter both groundwater supplies and surface water bodies from point and/or nonpoint sources. In urban areas,

\footnotetext{
*Corresponding author. Tel.: +90 232750 6648; fax: +90 2327506645 .

E-mail addresses: cemilsofuoglu@iyte.edu.tr, saitcemil@iit.edu (S.C. Sofuoglu). 0043-1354/\$ - see front matter (c) 2006 Elsevier Ltd. All rights reserved.
} doi:10.1016/j.watres.2006.07.002 
VOC concentrations in drinking water may be high due to oil spills and leakage from underground fuel/chemical storage tanks, whereas in rural areas, agricultural activities may lead to increased VOC levels. VOCs may also be released from the components of home distribution systems due to leaching of the plastic piping used in plumbing or from adhesives used in the original construction of the system (Hofer and Shuker, 2000; Squillace et al., 2002). Furthermore, the processes practiced in drinking water treatment plants (i.e., disinfection) and the chemicals added to the water for specific treatment goals may result in the production of specific VOC species. One such VOC group is trihalomethanes (THMs) produced by the reactions between disinfectants (i.e., chlorine) and the natural organic matter present in raw waters.

In general, VOCs are mostly found in groundwater, whereas THM levels are higher in surface waters (Kostopoulou et al., 1999; Hsu et al., 2001). Furthermore, the highest THM concentrations are observed in tap water since the reaction between free residual chlorine and natural organic matter continues throughout the distribution system, and chlorine is dosed at certain intervals/locations as a protection against waterborne diseases (Gelover et al., 2000; Golfinopoulos, 2000). THM concentrations may be as high as $300 \mu \mathrm{g} / \mathrm{l}$ (Fawell, 2000). Although individual THM species reported in previous studies usually do not exceed World Health Organisation (WHO) guideline values (WHO, 2004), some of the total THM (TTHM) concentrations found in tap water in New Jersey (Weisel et al., 1999), Australia (Simpson and Hayes, 1998), and Taiwan (Kuo et al., 1997) were above the United States Environmental Protection Agency (USEPA) maximum contaminant levels (MCLs). On the other hand, benzene and toluene concentrations fell below the MCLs as in the case of Arizona (Sofuoglu et al., 2003) and Taiwan (Kuo et al., 1997), although $>$ MCL values such as $38 \mu \mathrm{g} / \mathrm{l}$ have been reported for benzene (Gelover et al., 2000).

There are a few studies that measured THM and/or other VOC concentrations in drinking water, and estimated the health risks through ingestion route (Clayton et al., 1999; Hsu et al., 2001; Sofuoglu et al., 2003; Lee et al., 2004). While all estimates for noncarcinogenic risk were found to be less than the demarcation value of 1 , carcinogenic risk estimates both below and above the de minimis level of $10^{-6}$ have been reported. The highest estimated risk values were $1.8 \times 10^{-4}$ in Taiwan (Hsu et al., 2001) and $2.1 \times 10^{-7}$ in Arizona (Sofuoglu et al., 2003) for chloroform, and $6.82 \times 10^{-5}$ in Hong Kong (Lee et al., 2004) for bromodichloromethane.

THM concentrations were measured in finished waters and at points throughout the drinking water distribution systems in Ankara, Turkey (Capar and Yetis, 2002) and Istanbul, Turkey (Toroz and Uyak, 2005), but associated exposure and risks were not investigated. Recently, Tokmak et al. (2004) reported cancer risk levels for Ankara without considering the variation in the type of water drunk, drinking water consumption rate, and body weight (BW) in the population. There is a lack of information concerning exposure and risks associated with VOCs in drinking waters in Turkey. Izmir is the third largest city in Turkey where the majority of population is served by two surface water resources located in forested areas. This study aimed to measure the concentrations of THMs and other VOCs in İzmir drinking water, determine demographics and drinking water consumption rates, and estimate the individual and population-based oral exposure and associated risk levels for İzmir.

\section{Materials and methods}

İzmir, located about $550 \mathrm{~km}$ West of Ankara on the Aegean Sea shore, is the third largest city in Turkey with a population of approximately 3.5 millions. The majority of the population reside in the metropolitan area where drinking water is supplied mainly from two reservoirs after conventional treatment (Tahtali and Balcova dams, see Fig. 1). In addition, several groundwater wells (Goksu, Menemen, and Sarikiz) are used to support the main sources. A significant portion of metropolitan İmirians drink bottled spring water due to concerns about quality of the tap water. Typical Mediterranean climate is dominant with hot and humid summer days, rainy springs and falls, and temperatures rarely dropping below $0^{\circ} \mathrm{C}$ in winters.

\subsection{Sampling design and questionnaires}

A population weighted random sampling was used in this study. The number of samples, which also correspond to percentage of population, to be collected from each of 28 districts in the province was calculated according to the geographical population distribution (Fig. 1). Nine districts comprise the metropolitan area, four neighboring districts have industrial activity, and the remaining depend on agriculture or tourism. Houses (sampling units) to be visited in each district were selected randomly on the day of the sampling. In total, 100 houses were visited in different districts to collect drinking water samples from main drinking water sources, tap or other (generally bottled water).

For each sampling unit, one person was asked to be the primary participant and administer the questionnaires. The first questionnaire, which inquired about demographics of occupants, was administered by the authors during the visit. The participant was asked to declare personal information such as Body weight (BW), sex, age, education and income level, and homeland information, and information on the drinking water such as type and source. The second questionnaire was self-administered by the primary participant, for seven consecutive days starting on the day of the visit. The participant was asked to count the number of standard glasses $(200 \mathrm{ml})$ of water consumed during each day, remember the total number before going to sleep, and fill it in the corresponding field in the questionnaire. Dietary exposure due to use of drinking water in hot or cold beverages and food items such as soups was not estimated. The questionnaires used in this study were modified from the Baseline, Descriptive and Time-Activity Questionnaires used in National Human Exposure Assessment Study (NHEXAS)-Arizona study (Lebowitz et al., 1995) taking the lifestyle of Turkish people into consideration (Kavcar, 2005). Data collected from questionnaires included BW and daily intake (DI) rate, the two most important parameters to be used in estimating chronic daily exposure, and sex, age, education and income level, and homeland to analyze differences among population subgroups. 


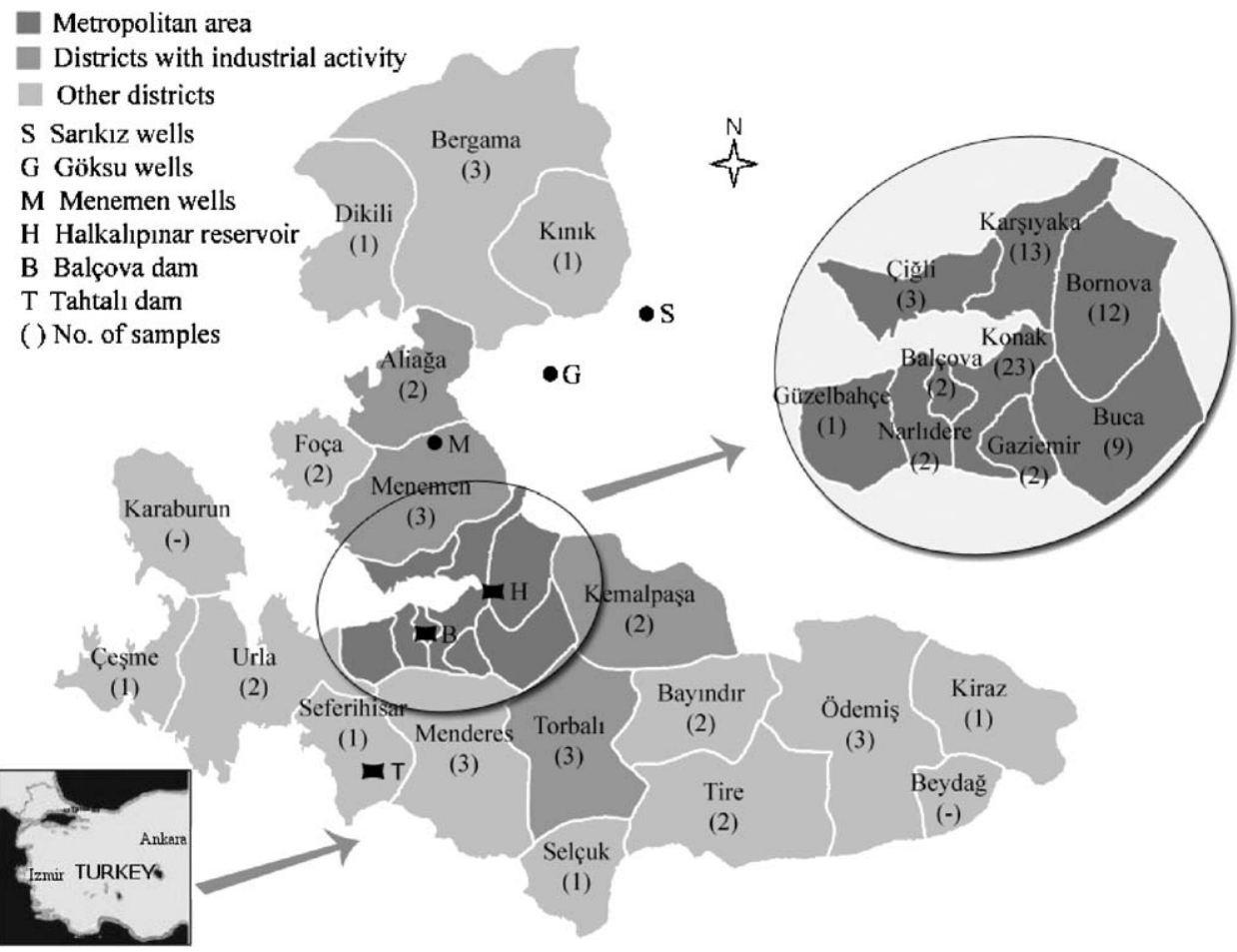

Fig. 1 - Location of province of İzmir, its districts, and sample sizes.

\subsection{Drinking water sampling}

For all analyses, sampling, and cleaning procedures, trace organic and chemical free MilliQ water (Millipore Elix 5) and high-purity solvents were used. All glasswares were washed with GC grade methanol (Merck, $\geqslant 99.9 \%$ ) and water prior to use and dried in an oven for $1 \mathrm{~h}$ at $105^{\circ} \mathrm{C}$. In each sampling unit, the primary participant was asked about the main drinking water source and samples were collected from tap or other sources accordingly. Duplicate samples $(10 \mathrm{ml})$ were collected from each sampling unit in 20-ml headspace vials (Agilent). Tap water samples were collected after 3-min flushing. The flow rate was reduced to avoid introducing bubbles during sampling. Bottled water samples were directly taken from containers. Ascorbic acid $(6.25 \mathrm{mg})$ (Fluka) was added to the vial as the quenching agent. A drop of 1:3 diluted hydrochloric acid (Merck, 37\%) was added to acidify the sample $(\mathrm{pH}<2)$. Residual chlorine concentration was determined using a DPD (diethyl-p-phenylene-diamine) test kit (Riedel-de Haën) prior to sampling and another $6.25 \mathrm{mg}$ ascorbic acid was added if the residual chlorine exceeded $5 \mathrm{mg} / \mathrm{l}$. The vials were immediately sealed with $20-\mathrm{mm}$ aluminum crimp caps (Agilent) with Teflon-faced septa (Agilent) and shaken to mix the content. All samples were transported in cooled containers and stored in the dark at $4{ }^{\circ} \mathrm{C}$ for a maximum of 5 days.

\subsection{Analytical methods}

Drinking water samples were analyzed for 54 VOCs (USEPA, $1992 b)$ using a gas chromatograph (Agilent 6890N) equipped with an automated headspace sampler (Agilent 7694) and a mass selective detector (Agilent 5973N MSD). Liquid VOC mixture (ChemService) containing the 54 VOCs in methanol was used as the stock standard solution. Primary dilution standards were prepared at concentrations which could be easily diluted to prepare aqueous calibration solutions that would bracket the working concentration range. Aqueous calibration standards were prepared by injecting appropriate volumes of primary dilution standards into headspace vials containing $10 \mathrm{ml}$ acidified $(\mathrm{pH}<2)$ pure water and $6.25 \mathrm{mg}$ ascorbic acid. The final concentrations of the calibration standards were $1,5,25,50$, and $100 \mu \mathrm{g} / \mathrm{l}$. The $R^{2}$ values for the calibration curves were between 0.996 and 0.999 for all VOCs.

Oven, loop, and transfer line temperatures of the headspace sampler were 90,95 , and $100^{\circ} \mathrm{C}$, respectively. GC cycle, vial equilibration, pressurizing, loop fill, loop equilibration, and inject times were 50,15, 0.05, 0.05, 0.05, and $3 \mathrm{~min}$, respectively. The chromatographic column was HP5-ms $(30 \mathrm{~m}$, $0.25 \mathrm{~mm}, 0.25 \mu \mathrm{m}$ ) and the carrier gas was helium at $0.9 \mathrm{ml} /$ min. The inlet temperature was $240^{\circ} \mathrm{C}$ and the split ratio was 1:40. Temperature program was: initial oven temperature $40^{\circ} \mathrm{C}$, hold for $3 \mathrm{~min}, 40-120^{\circ} \mathrm{C}$ at $5^{\circ} \mathrm{C} / \mathrm{min}$, hold $2 \mathrm{~min}$, $120-150^{\circ} \mathrm{C}$ at $10^{\circ} \mathrm{C} / \mathrm{min}$. Ionization mode of the MS was electron impact (EI). Ion source, quadropole, and GC/MSD interface temperatures were 230,150 , and $280^{\circ} \mathrm{C}$, respectively. The MSD was run in selective ion monitoring (SIM). Compounds were identified based on their retention times (within $\pm 0.05 \mathrm{~min}$ of the retention time of calibration standard), target and qualifier ions. Identified compounds were quantified using the external standard calibration procedure. In order to determine the detection limits (DLs), aqueous solutions were prepared with concentrations close to the expected DLs. Fourteen solutions with varying concentrations 
between 0.01 and $0.5 \mu \mathrm{g} / \mathrm{l}$ were analyzed and the DLs were calculated from those peaks for which the signal-to-noise ratio was at least 3:1. After every 10 samples, a standard was analyzed as a sample. If the variation between this sample and standard concentration was more than $10 \%$, the instrument was recalibrated. Difference between duplicate samples (i.e., two separate samples taken at the same time, $n=10$ ) was $12 \pm 7 \%$ (mean \pm standard deviation). Among the eight most detected VOCs only toluene and naphthalene were detected in laboratory blanks of which concentrations were six and nine times smaller than the average concentration, respectively. In addition to the above two compounds, benzene and $p$-xylene were detected in field blanks in which concentrations were 3.0-4.5 times smaller than the mean concentration with an average of 3.8 .

\subsection{Statistical methods}

Since all VOCs were not detected in all samples, concentration data had to be censored to avoid overestimation of exposure and risk. A robust method was used to censor the data. Probability distributions were fitted to the detected concentrations of each VOC, then values were generated for the nondetects by extrapolating below DL. Generated concentrations were then used in exposure and risk calculations along with the measured concentrations.

Statistical analyses were performed using SPSS (Release 12.0); Monte Carlo simulations were performed using Crystal Ball (v 4.0e) software. Monte Carlo Simulation is a computer-based method of analysis that uses statistical sampling techniques in obtaining a probabilistic approximation to the solution of a mathematical equation or model (USEPA, 1997b). For each variable in an equation, the possible values are defined with a probability distribution. The probability distributions were determined by fitting select distributions to measured/surveyed data by the help of goodness-of-fit tests which were chi-square, Kolmogorov-Smirnov, and Anderson-Darling tests. The simulation software is used in fitting distributions, which provides values of the test statistics, and allows the user to determine the best fitting distribution. These probability distributions are used as the input distributions for exposure model parameters. During a single trial, values are randomly selected from the defined possibilities (the range and shape of the distribution) for each uncertain variable and then the output of the model is calculated. If a simulation is run for 10,000 trials, 10,000 forecasts (or possible outcomes) are created compared to the single outcome obtained in the deterministic approach. Exposure and risk distributions of İzmir population were estimated using the simulated values $(n=10,000)$.

Kruskal-Wallis and Mann-Whitney tests were used to determine whether the concentrations of VOCs found in drinking water and risk associated with exposure to these VOCs differed across population subgroups. Kruskal-Wallis test was applied to the data sets with more than two subgroups to test the null hypothesis that all subgroups have identical distribution functions against the alternative hypothesis that at least two of the samples differ only with respect to location (median), if at all. On the other hand,
Mann-Whitney test, also known as the Wilcoxon rank sum test, was used to test for difference between the medians of two subgroups. In this study, $p$-values $<0.05$ were considered to point a significant difference between the compared subgroups.

\subsection{Exposure and risk assessment}

In order to estimate the daily exposure of an individual, USEPA (1999a) suggests the Lifetime Average Daily Dose (LADD) as the exposure metric. The following equation is a similar representation of daily exposure for ingestion route modified from USEPA (1992a) and Chrostowski (1994):

$\mathrm{CDI}=\frac{\mathrm{C} \times \mathrm{DI}}{\mathrm{BW}}$,

where CDI is the chronic DI (mg/kg/d), C is the drinking water contaminant concentration ( $\mathrm{mg} / \mathrm{l})$, DI is the average DI rate of drinking water $(\mathrm{l} / \mathrm{d})$, and $\mathrm{BW}$ is in $(\mathrm{kg})$. Values of these three input variables, specific to each subject, were used to estimate the subject individual's chronic daily exposure level. Deterministic exposure assessment involved using Eq. (1) to estimate individual exposures to each VOC.

Lifetime cancer risk associated with ingestion exposure is calculated using the following equation (Patrick, 1994; USEPA, 1999a):

$\mathrm{R}=\mathrm{CDI} \times \mathrm{SF}$,

where $R$ is the probability of excess lifetime cancer (or simply risk), CDI is the chronic DI (mg/kg/d), and SF is the slope factor of the chemical $(\mathrm{mg} / \mathrm{kg} / \mathrm{d})^{-1}$.

To estimate noncarcinogenic risk, the hazard quotient (HQ) is calculated using the following equation (USEPA, 1999b):

$\mathrm{HQ}=\frac{\mathrm{CDI}}{\mathrm{RfD}}$,

where RfD is the reference dose (mg/kg/d). SF and RfD values employed in this study were obtained from USEPA (IRIS, 2005).

\section{Results and discussion}

\subsection{VOC concentrations}

At least one VOC was detected in all of the drinking water samples. Sixty-nine percent of the samples contained up to eight different VOC species, whereas nine or more VOCs were detected in $31 \%$ of the samples. The maximum number of VOCs detected in a single sample was $15(n=3)$. The most of the 54 VOCs were below DL in the most of the samples. The most frequently $(\geqslant 45 \%)$ detected VOCs were the four THM species (i.e., chloroform $71 \%$, bromodichloromethane $46 \%$, dibromochloromethane 47\%, and bromoform 45\%), and benzene $(47 \%)$, toluene (96\%), p-xylene (74\%), and naphthalene $(70 \%)$, therefore, exposure and risk assessment is discussed only for these VOCs in this article. VOC concentrations ranged from below DL to $35 \mu \mathrm{g} / \mathrm{l}$ with none of the samples exceeding the WHO guideline values (WHO, 2004) or Turkish (Ministry of Health, 2005), American (USEPA 2002a; USEPA, 2002b), or European (The European Communities 
(Drinking Water) Regulations, 2000) standards. Only one sample exceeded the TTHM MCL of $80 \mu \mathrm{g} / \mathrm{l}$ established by the USEPA.

DLs and descriptive statistics of concentrations after censoring are presented in Table 1 . The median, mean, and 90th percentile values of VOC concentrations obtained in this study were much less than almost all of those reported in the literature. The exception was the mean and 90th percentile chloroform concentrations reported in the NHEXAS-Arizona study for both tap and nontap water (Sofuoglu et al., 2003). For benzene, Robertson et al. (1999) reported a median concentration below the DL of $0.03 \mu \mathrm{g} / \mathrm{l}$ and a 90th percentile concentration of $0.04 \mu \mathrm{g} / \mathrm{l}$ as part of the same study, both of which lie below the corresponding values obtained in this study.

Information gathered from questionnaires was examined and concentration data for each VOC were compared for subgroups for six categories; sex, area, water source, education level, homeland, and income level. The data obtained from the questionnaires are summarized in Table 2. The drinking water source of each participant was classified as (1) tap water or (2) nontap water, which included purchased bottled water, water pumped from private wells, and all other sources. Thirty-five percent of the participants consumed nontap water among which $80 \%$ was bottled water. The remaining ones categorized as "other" were water collected into bottles from a close-by spring. All THM species were detected in higher concentrations in tap water, whereas nontap water contained more toluene and naphthalene, and concentrations were about the same for benzene and $p$-xylene (Table 3). Median concentration differences between tap and nontap water were larger for THMs compared to the other four VOCs. While the difference ranged from 5.5 times for chloroform to 58.3 times for DBCM, it was 2 and 3 times for toluene and naphthalene, respectively. The difference was $<10 \%$ for benzene and $p$-xylene. Mann-Whitney test results suggested that the difference between tap and nontap water was significant for all VOCs except benzene $(p=0.74)$. The concentrations of THMs found in Izmir tap water were much less than the concentrations reported by Tokmak et al. (2004). The relatively high concentrations detected in Ankara tap water is probably due to differences in raw water characteristics, especially the amount and type of natural organic matter, and differences in chlorination practices between plants in Ankara and İzmir. Residual chlorine was found to be $<1 \mathrm{mg} / \mathrm{L}$ in $99 \%$ of the houses visited in İzmir.

\section{Table 1 - Descriptive statistics of VOC concentrations after censoring}

\begin{tabular}{|c|c|c|c|c|c|c|c|c|}
\hline VOC & $\mathrm{DL}^{\mathrm{a}}$ & Median & Mean & $\mathrm{SD}^{\mathrm{b}}$ & Min & Max & 90th percentile & 95th percentile \\
\hline Chloroform & 0.02 & 0.04 & 4.41 & 9.36 & $3.84 \mathrm{E}-11$ & 34.58 & 24.28 & 27.49 \\
\hline BDCM & 0.03 & 0.02 & 3.73 & 7.78 & $1.58 \mathrm{E}-07$ & 27.45 & 21.23 & 22.93 \\
\hline DBCM & 0.04 & 0.03 & 2.61 & 5.20 & $4.09 \mathrm{E}-07$ & 17.93 & 13.48 & 15.02 \\
\hline Bromoform & 0.09 & 0.08 & 0.62 & 0.95 & $2.02 \mathrm{E}-04$ & 4.19 & 2.12 & 2.57 \\
\hline Benzene & 0.02 & 0.02 & 0.03 & 0.02 & 0.010 & 0.10 & 0.06 & 0.07 \\
\hline Toluene & 0.01 & 0.05 & 0.09 & 0.18 & 0.007 & 1.60 & 0.16 & 0.43 \\
\hline$p$-Xylene & 0.01 & 0.01 & 0.01 & 0.01 & 0.001 & 0.05 & 0.02 & 0.03 \\
\hline Naphthalene & 0.01 & 0.03 & 0.06 & 0.13 & 0.004 & 0.90 & 0.11 & 0.20 \\
\hline
\end{tabular}

\section{$\mathrm{N}=100$.}

All values are in $\mu \mathrm{g} / \mathrm{l}$.

a Detection limit.

b Standard deviation.

Table 2 - Summary of questionnaire data

\begin{tabular}{|c|c|c|c|c|c|c|c|c|c|c|c|}
\hline \multicolumn{2}{|l|}{ Sex } & \multicolumn{2}{|l|}{ Age } & \multicolumn{2}{|l|}{ Education } & \multicolumn{2}{|c|}{ Income } & \multicolumn{2}{|l|}{ Homeland } & \multicolumn{2}{|c|}{ Source of DW } \\
\hline Category & $\%$ & Category & $\%$ & Category & $\%$ & Category & $\%$ & Category & $\%$ & Category & $\%$ \\
\hline Female & 60 & $15-20$ & 12 & Primary school & 23 & $0-300$ & 9 & Aegean & 63 & Tap & 65 \\
\hline \multirow[t]{7}{*}{ Male } & 40 & $21-25$ & 20 & Middle school & 11 & $300-600$ & 25 & Marmara & 2 & Bottle & 27 \\
\hline & & $26-35$ & 29 & High school & 30 & $600-1000$ & 28 & Western Black Sea & 1 & Private Well & 1 \\
\hline & & $36-45$ & 20 & Undergraduate & 28 & $1000-2000$ & 27 & Eastern Black Sea & 3 & Other & 7 \\
\hline & & $46-55$ & 9 & Graduate & 8 & $>2000$ & 11 & Eastern Anatolia & 15 & & \\
\hline & & $56-65$ & 5 & & & & & Southeastern Anatolia & 3 & & \\
\hline & & $>65$ & 3 & & & & & Mediterranean & 1 & & \\
\hline & & & & & & & & Central Anatolia & 12 & & \\
\hline
\end{tabular}


Table 3 - Median and mean VOC concentrations across source and area subgroups

\begin{tabular}{|c|c|c|c|c|c|c|c|}
\hline VOC & Source/area & Median & Mean & VOC & Source/area & Median & Mean \\
\hline \multirow[t]{4}{*}{ Chloroform } & Tap & 0.110 & 6.347 & Benzene & Tap & 0.019 & 0.028 \\
\hline & Nontap & 0.020 & 0.812 & & Nontap & 0.020 & 0.029 \\
\hline & Metropolitan & 0.110 & 6.172 & & Metropolitan & 0.030 & 0.033 \\
\hline & Other & 0.007 & 0.833 & & Other & 0.017 & 0.020 \\
\hline \multirow[t]{4}{*}{ BDCM } & Tap & 0.130 & 5.384 & Toluene & Tap & 0.030 & 0.088 \\
\hline & Nontap & 0.003 & 0.653 & & Nontap & 0.060 & 0.087 \\
\hline & Metropolitan & 0.130 & 5.212 & & Metropolitan & 0.060 & 0.107 \\
\hline & Other & 0.011 & 0.716 & & Other & 0.020 & 0.051 \\
\hline \multirow[t]{4}{*}{ DBCM } & Tap & 0.350 & 3.797 & $p$-Xylene & Tap & 0.010 & 0.012 \\
\hline & Nontap & 0.006 & 0.408 & & Nontap & 0.011 & 0.015 \\
\hline & Metropolitan & 0.280 & 3.626 & & Metropolitan & 0.010 & 0.014 \\
\hline & Other & 0.009 & 0.548 & & Other & 0.009 & 0.011 \\
\hline \multirow[t]{4}{*}{ Bromoform } & Tap & 0.400 & 0.902 & Naphthalene & Tap & 0.020 & 0.029 \\
\hline & Nontap & 0.057 & 0.104 & & Nontap & 0.060 & 0.126 \\
\hline & Metropolitan & 0.180 & 0.767 & & Metropolitan & 0.040 & 0.084 \\
\hline & Other & 0.068 & 0.331 & & Other & 0.009 & 0.021 \\
\hline
\end{tabular}

Each district of İzmir was placed in one of the following subgroups: (1) metropolitan area in which tap water is served by Izmir Metropolitan Municipality (Fig. 1) and (2) other districts. For all VOCs, concentrations found in metropolitan area were greater than those in other districts (Table 3). The difference was not significant at the presumed significance level for bromoform only $(p=0.10)$. Health risks due to oral exposure to THMs were higher for people who consumed tap water, while risks associated with toluene, $p$-xylene, and naphtalene were higher for nontap water drinkers. Risks from oral exposure to benzene in tap and nontap were not statistically different. Meanwhile, for all VOCs, risks were higher in the metropolitan area. When the data were stratified according to area, THM risk levels were higher for tap water in both metropolitan and other districts except for bromoform for which the risks were comparable. Risks associated with oral exposure to benzene, toluene, and $p$-xylene in tap and nontap waters were comparable in both metropolitan and the other districts. However, naphthalene risk was higher for nontap in both subgroups. These comparisons showed that the tap-nontap water difference in risk levels for benzene, toluene, and $p$-xylene is in fact due to the effect of the area, but for the remaining ones area has no effect on the discussed differences.

Results of the hypothesis tests are tabulated for education level, homeland, and income level categories (Table 4). Education level was investigated in three subgroups; (1) up to high school, (2) high school graduate, and (3) technical school/college graduate. Bromoform concentration in the first subgroup was significantly higher than the other subgroups. For toluene, $p$-xylene, and naphthalene, concentrations increased with education level with significant differences especially between the first and third subgroups. Tests were applied to only three groups in homeland category due to sample size limitations: (1) Aegean Region; (2) Central Anatolia Region; and (3) Eastern Anatolia Region. Across these subgroups, the concentrations for benzene, toluene, $p$ xylene, and naphthalene were very close with high $p$-values (Table 4). On the other hand, THM concentrations increased form Eastern Anatolia to Aegean Region. The differences were significant especially between the Aegean Region and the Eastern Anatolia Region according to the Mann-Whitney test results. In order to determine the income level for each house, monthly income of every individual living in that house was summed up. The income level was examined in three subgroups; (1) low, 0-600 YTL; (2) medium, 600-2000 YTL, and (3) high, $>2000$ YTL ( 1 USD = 1.35 YTL). For benzene and the four THM species, the concentrations did not differ across these subgroups. However, the concentrations for toluene, $p$ xylene, and naphthalene increased as the income level increased. Mann-Whitney test results revealed that the differences were significant between the subgroups 1 and 2 and 1 and 3 . The test results, also, revealed that the concentration of VOCs found in İzmir drinking water did not differ between the sex categories; all $p$-values were $>0.24$. In addition, the issue of whether the source of drinking water differs among population subgroups was investigated. It was found that percentage of tap water drinking participants reduced with increasing education level $(77 \%$ on average for up to high school and 33\% on average for undergrad or grad education). Similarly, ratio of participants drinking tap water reduced with increasing income $(80 \%$ on average for 0-1000 YTL, 55\% for 1000-2000 YTL, 9\% for >2000 YTL). However, the majority of participants were drinking tap water regardless of homeland (58\% for Aegean region, $77 \%$ on average for Central and Eastern Anatolia regions). Therefore, the differences in population subgroup VOC concentrations may be attributed to the type of water drunk for education and income categories. 
Table 4 - Comparison of population subgroups for VOC concentrations

\begin{tabular}{|c|c|c|c|c|}
\hline Category & & Education level & Homeland & Income level \\
\hline Subgroups & & $\begin{array}{l}\text { Up to high school/ } \\
\text { High school grad/ } \\
\text { Tech or college }\end{array}$ & $\begin{array}{c}\text { Aegean/ } \\
\text { Central Anatolia/ } \\
\text { Eastern Anatolia }\end{array}$ & $\begin{array}{l}\text { Low/ } \\
\text { Medium/ } \\
\text { High }\end{array}$ \\
\hline Sample sizes & & $34 / 30 / 36$ & $63 / 12 / 15$ & $34 / 55 / 11$ \\
\hline \multirow[t]{8}{*}{$p$-values } & Chloroform & 0.334 & 0.048 & 0.217 \\
\hline & BDCM & 0.096 & 0.062 & 0.065 \\
\hline & DBCM & 0.201 & 0.009 & 0.375 \\
\hline & Bromoform & 0.026 & 0.034 & 0.066 \\
\hline & Benzene & 0.630 & 0.432 & 0.911 \\
\hline & Toluene & 0.005 & 0.962 & 0.004 \\
\hline & p-Xylene & 0.006 & 0.644 & 0.013 \\
\hline & Naphthalene & $<0.001$ & 0.643 & 0.002 \\
\hline
\end{tabular}

\subsection{Average DI rate}

DI was calculated by averaging the self-reported number of standard (200-ml) glasses of water drunk per day for seven consecutive days in the week of sampling. The number of standard (200-ml) glasses of water drunk per day for seven consecutive days in the week of sampling was reported, then these values were converted to liters, and the resultant frequency distribution for average daily intake rate of drinking water (DI) was plotted as shown in Fig. 2a. DI was in the range of $0.4-6.0 \mathrm{l} / \mathrm{d}$. The median and mean DI values (1.8 and $1.9 \mathrm{l} / \mathrm{d}$, respectively) for İzmir population were found to be half a liter greater than the corresponding statistics of the American adults (USEPA, 1997a), and lie between the values reported in the literature. DI varies in the population; 90th and 95th percentile values were 3.2 and $4.4 \mathrm{l} / \mathrm{d}$, respectively. On the other hand, single DI values used in risk assessment studies may lead to over/underestimation of risk. Lee et al. (2004) used 4.48 l/d and Tokmak et al. (2004) assumed the USEPA suggested DI value of $2 \mathrm{l} / \mathrm{d}$ which does not seem reasonable for Ankara population. In fact, USEPA (2004) recently reiterated the average DI for the American population, and suggested that 21 is high for daily drinking water consumption but it is a better estimate for total daily liquid intake. The intake rate, presumably, varies with climate; and $21 / d$ is rather close to the mean DI value calculated for İzmir, which has a hotter climate with high humidity compared to Ankara. Our sampling campaign continued from September 2004 to January 2005, which covered hot summer to cold winter conditions, therefore, we believe that the calculated statistics are realistic estimations of annual average values of İzmir population.

\subsection{Body weight}

The BW of each participant was recorded during the administration of the Descriptive Questionnaire. Frequency distribution and descriptive statistics for BW are presented in Fig. 2b. BWs of $62 \%$ of the participants were between 50 and $70 \mathrm{~kg}$, while the portion of participants with a BW between 70 and $90 \mathrm{~kg}$ was $23 \%$. The median and mean BWs for İzmir population were found to be less than the value, $70 \mathrm{~kg}$, suggested by the USEPA and used in the literature (Williams et al., 2002; Lee et al., 2004). Tokmak et al. (2004) used BW of $65 \mathrm{~kg}$ for females and $72 \mathrm{~kg}$ for males for Ankara residents. In this study, the median and mean values were calculated as 58 and $60 \mathrm{~kg}$ for females and as 74.5 and $73.9 \mathrm{~kg}$ for males. If the BW were assumed to be $70 \mathrm{~kg}$ for İzmir population, exposure and risk would have been underestimated for female participants and overestimated for male participants.

\subsection{Exposure assessment}

Exposure may occur via three main routes; ingestion, inhalation, and dermal absorption. The other two routes, especially inhalation, can be as important as ingestion; however, in this study VOC concentrations were measured only in drinking water, therefore, only the ingestion route was taken into consideration in the assessment. Since a large proportion of the 54 VOCs were below the DLs, exposure and risk assessments were carried out for the most frequently detected eight VOCs due to statistical limitations. CDI values were calculated for each participant and the statistics are presented in Table 5. The deterministic CDI statistics reported by Sofuoglu et al. (2003) were compared to the values calculated for chloroform and toluene in this study. The median, mean, and 90th percentile CDI values of chloroform found in this study are greater than those found in NHEXAS for Arizona and border populations. Toluene CDI statistics for İzmir and NHEXAS border populations were almost equal, whereas the values calculated for the Arizona population were much greater.

In order to estimate exposure probabilistically, Monte Carlo Simulation was run using the fitted probability distributions for VOC concentrations, BW, and average daily intake rate of drinking water as the input variables. The best fitting 

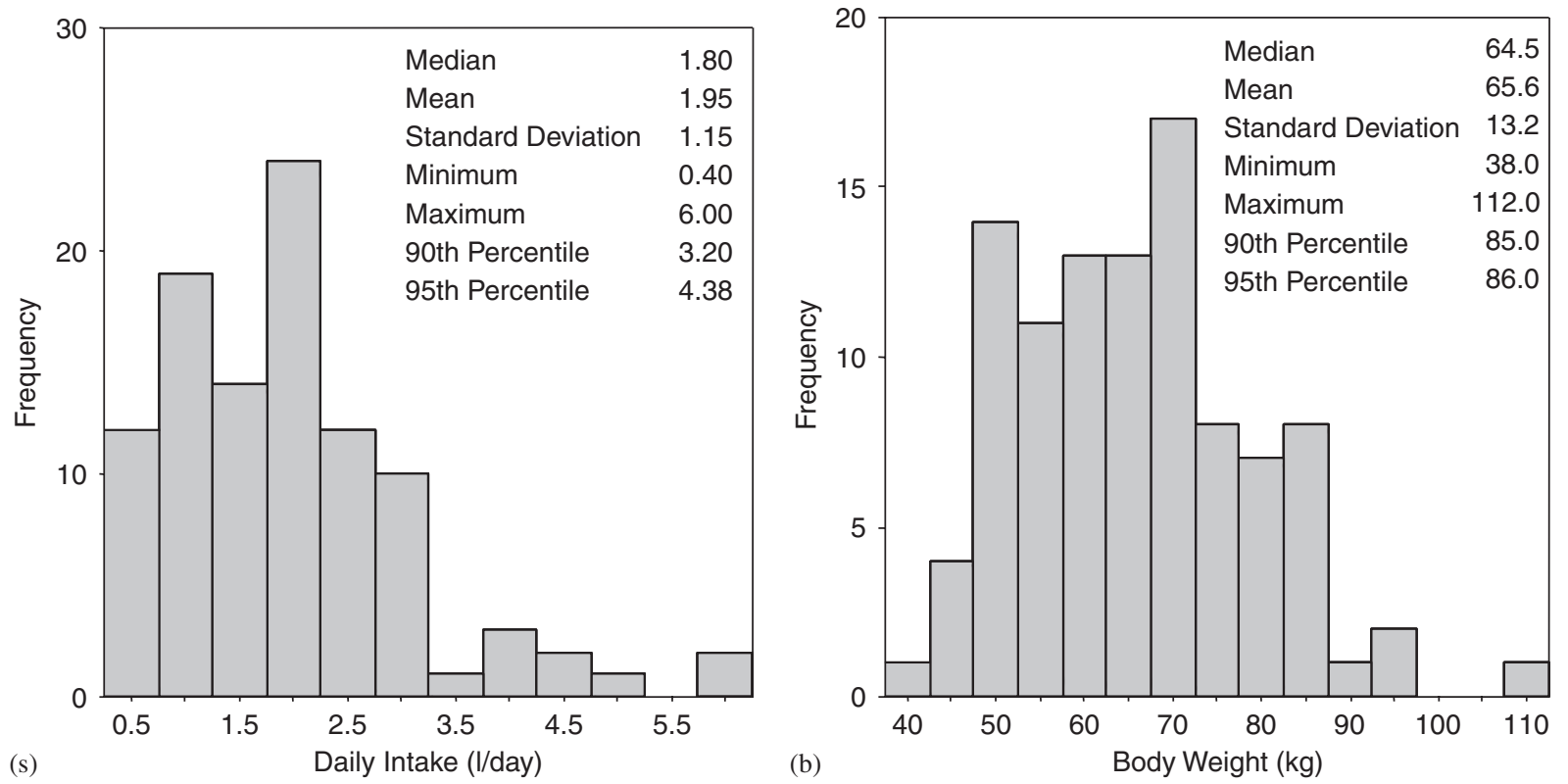

Fig. 2 - Frequency histograms and descriptive statistics of (a) daily intake and (b) body weight.

Table 5 - Descriptive statistics for deterministic exposure assessment (CDI values)

\begin{tabular}{|c|c|c|c|c|c|c|c|}
\hline VOC & Median & Mean & $\mathrm{SD}^{\mathrm{a}}$ & Min & Max & 90th percentile & 95th percentile \\
\hline Chloroform & 0.0012 & 0.1280 & 0.3070 & $9.95 \mathrm{E}-13$ & 1.301 & 0.582 & 0.986 \\
\hline BDCM & 0.0006 & 0.1088 & 0.2666 & 5.17E-09 & 1.501 & 0.397 & 0.772 \\
\hline DBCM & 0.0015 & 0.0769 & 0.1921 & $7.16 \mathrm{E}-09$ & 1.233 & 0.331 & 0.522 \\
\hline Bromoform & 0.0027 & 0.0184 & 0.0378 & $9.39 \mathrm{E}-06$ & 0.264 & 0.066 & 0.084 \\
\hline Benzene & 0.0006 & 0.0009 & 0.0008 & $7.84 \mathrm{E}-05$ & 0.005 & 0.002 & 0.002 \\
\hline Toluene & 0.0011 & 0.0028 & 0.0074 & $3.19 \mathrm{E}-05$ & 0.069 & 0.005 & 0.010 \\
\hline$p$-Xylene & 0.0003 & 0.0004 & 0.0003 & $1.76 \mathrm{E}-05$ & 0.002 & 0.001 & 0.001 \\
\hline Naphthalene & 0.0007 & 0.0022 & 0.0057 & $4.09 \mathrm{E}-05$ & 0.039 & 0.003 & 0.006 \\
\hline \multicolumn{8}{|c|}{$\begin{array}{l}\mathrm{N}=100 . \\
\text { All values are in } \mu \mathrm{g} / \mathrm{Kg} / \mathrm{d} \text {. } \\
\text { a Standard deviation. }\end{array}$} \\
\hline
\end{tabular}

distributions and values of distribution parameters are presented in Table 6. Ten thousand trials were run for each VOC and resultant probability distributions were constructed. In Table 7, the statistics extracted from Monte Carlo Simulation run are shown. The median, mean, and 90th percentile CDI values for chloroform and toluene given in the table were compared to the values reported by Sofuoglu et al. (2003) using the probabilistic approach. Chloroform CDI statistics for the NHEXAS-Arizona study were less than the values obtained in this study, while for toluene the opposite was observed.

\subsection{Risk assessment}

Carcinogenic and noncarcinogenic risks attributable to chloroform, bromodichloromethane, dibromochloromethane, bromoform, benzene, toluene, $p$-xylene, and naphthalene were assessed using both deterministic and probabilistic approaches. Risk values greater than 1 in a million $\left(10^{-6}\right)$ are generally considered unacceptable by the USEPA (2000a). However, this acceptable level may change according to national standards and environmental policies and may be as high as $10^{-4}$ (Health Canada, 1998; USEPA, 2000b; WHO, 2004). HQ values greater than one indicate a potential for an adverse effect to occur or the need for further study. For İzmir drinking water, however, the deterministically calculated HQ values pointed out negligible noncarcinogenic risks. Even the maximum HQ value for chloroform was almost 10 times less than one. Similar results were obtained from the simulated risks for the İmir population with chloroform having the highest risk among the studied VOCs (95th percentile value of $0.07)$ that is much smaller than the demarcation value. While 


\section{Table 6 - The best-fitting distributions and values of their parameters for Monte Carlo simulation input variables}

\begin{tabular}{|c|c|c|c|c|}
\hline Input variable & Distribution & Parameter- $1^{\mathrm{a}}$ & Parameter- $2^{\mathrm{b}}$ & Parameter- $3^{c}$ \\
\hline Chloroform & Gamma & 0.00 & 29.12 & 0.1515 \\
\hline BDCM & Gamma & 0.00 & 23.71 & 0.1572 \\
\hline DBCM & Gamma & 0.00 & 13.61 & 0.1918 \\
\hline Bromoform & Beta & 0.32 & 4.08 & 8.46 \\
\hline Benzene & Lognormal & 0.03 & 0.02 & - \\
\hline Toluene & Lognormal & 0.08 & 0.10 & - \\
\hline p-Xylene & Beta & 1.92 & 13.11 & 0.10 \\
\hline Naphthalene & Lognormal & 0.05 & 0.09 & - \\
\hline Daily Intake & Lognormal & 1.99 & 1.39 & - \\
\hline Body Weight & Lognormal & 65.6 & 13.0 & - \\
\hline \multicolumn{5}{|c|}{$\begin{array}{l}\text { a Location for gamma distribution, alpha for beta distribution, mean for lognormal distribution. } \\
\text { b Scale for gamma distribution, beta for beta distribution, standard deviation for lognormal distribution. } \\
\text { c Shape for gamma distribution, scale for beta distribution. }\end{array}$} \\
\hline
\end{tabular}

Table 7 - Descriptive statistics for probabilistic exposure assessment (CDI values)

\begin{tabular}{|c|c|c|c|c|c|c|c|}
\hline VOC & Median & Mean & $\mathrm{SD}^{\mathrm{a}}$ & Min & $\operatorname{Max}$ & 90th percentile & 95th percentile \\
\hline Chloroform & 0.0050 & 0.1403 & 0.4801 & $1.78 \mathrm{E}-13$ & 16.819 & 0.359 & 0.697 \\
\hline BDCM & 0.0051 & 0.1120 & 0.3621 & $6.33 \mathrm{E}-10$ & 7.885 & 0.312 & 0.624 \\
\hline DBCM & 0.0060 & 0.0811 & 0.2665 & $2.09 \mathrm{E}-09$ & 813.997 & 0.224 & 0.399 \\
\hline Bromoform & 0.0047 & 0.0193 & 0.0393 & $4.59 \mathrm{E}-14$ & 1.089 & 0.054 & 0.089 \\
\hline Benzene & 0.0006 & 0.0009 & 0.0009 & $2.24 \mathrm{E}-05$ & 0.020 & 0.002 & 0.002 \\
\hline Toluene & 0.0012 & 0.0024 & 0.0040 & $9.94 \mathrm{E}-06$ & 0.071 & 0.005 & 0.008 \\
\hline$p$-Xylene & 0.0003 & 0.0004 & 0.0004 & $1.22 \mathrm{E}-06$ & 0.008 & 0.001 & 0.001 \\
\hline Naphthalene & 0.0008 & 0.0017 & 0.0033 & $1.06 \mathrm{E}-06$ & 0.083 & 0.004 & 0.007 \\
\hline \multicolumn{8}{|c|}{$\begin{array}{l}N=10000 . \\
\text { All values are in } \mu \mathrm{g} / \mathrm{Kg} / \mathrm{d} \text {. } \\
\text { a Standard deviation. }\end{array}$} \\
\hline
\end{tabular}

similar results were reported for Arizona (Sofuoglu et al., 2003), Lee et al. (2004) have reported HQ values as high as 0.48 for chloroform and 0.52 for TTHMs. The reasons for these relatively high estimates are that the THM concentrations found in Hong Kong drinking water and the average daily intake rate used to estimate CDI values were well above those found in İzmir.

Cancer risks could not be calculated for chloroform, toluene, $p$-xylene, and naphthalene since SFs were not available for these VOCs. The USEPA (IRIS, 2005) indicates that chloroform is considered likely to be carcinogenic to humans by all routes of exposure under high-exposure conditions that lead to cytotoxicity and regenerative hyperplasia in susceptible tissues. However, chloroform is not likely to be carcinogenic to humans by any route of exposure under lower exposure conditions that do not cause cell toxicity and abnormal growth/regeneration. Therefore, former oral SF of $0.031(\mathrm{mg} / \mathrm{kg} / \mathrm{d})^{-1}$ was withdrawn and a dose of $0.01 \mathrm{mg} / \mathrm{kg} / \mathrm{d}$ (equal to the RfD) was considered protective against cancer risk. A range is given for the SF of benzene (IRIS, 2005); the upper limit of the given range was used in calculations. In Table 8 , the statistics are presented for deterministic and probabilistic estimations of carcinogenic risk.
Estimated individual lifetime cancer risks were compared to the de minimis risk. The median, mean, 90th percentile, and 95th percentile cancer risks for benzene and bromoform, and the median cancer risks for BDCM and DBCM were below the stated level. The mean, 90th percentile, and 95th percentile cancer risks for BDCM and DBCM, however, exceeded this level. While all of the $R$ values calculated for benzene were less than $10^{-6} ; 23 \%, 29 \%$, and $2 \%$ of individuals had lifetime cancer risks above this value for BDCM, DBCM, and bromoform, respectively.

The differences between the carcinogenic risks estimated by deterministic and probabilistic approaches were not as small as the differences between deterministically and probabilistically estimated noncarcinogenic risks. For BDCM, DBCM, and bromoform, probabilistic approach resulted in higher estimates for median and mean R's while 90th and 95th percentile values were lower compared to those estimated deterministically. For benzene, however, the opposite was correct and the differences were relatively smaller. Sofuoglu et al. (2003) have pointed out similar differences for carcinogenic risks estimated deterministically and probabilistically, and recommended that the deterministic approach should be preferred whenever data were available in 
Table 8 - Descriptive statistics for deterministic and probabilistic carcinogenic risk assessment

\begin{tabular}{|c|c|c|c|c|c|c|c|}
\hline VOC & Median & Mean & $\mathrm{SD}^{\mathrm{a}}$ & Min & $\operatorname{Max}$ & 90th percentile & 95th percentile \\
\hline \multicolumn{8}{|c|}{ Deterministic approach $(N=100)$} \\
\hline BDCM & $3.75 \mathrm{E}-08$ & $6.74 \mathrm{E}-06$ & $1.65 \mathrm{E}-05$ & $3.21 \mathrm{E}-13$ & $9.31 \mathrm{E}-05$ & $2.46 \mathrm{E}-05$ & $4.78 \mathrm{E}-05$ \\
\hline $\mathrm{DBCM}$ & $1.24 \mathrm{E}-07$ & $6.46 \mathrm{E}-06$ & $1.61 \mathrm{E}-05$ & $6.02 \mathrm{E}-13$ & $1.04 \mathrm{E}-04$ & $2.78 \mathrm{E}-05$ & $4.38 \mathrm{E}-05$ \\
\hline Bromoform & $2.10 \mathrm{E}-08$ & $1.46 \mathrm{E}-07$ & $2.99 \mathrm{E}-07$ & $7.42 \mathrm{E}-11$ & $2.09 \mathrm{E}-06$ & $5.18 \mathrm{E}-07$ & $6.63 \mathrm{E}-07$ \\
\hline Benzene & $3.46 \mathrm{E}-08$ & $4.69 \mathrm{E}-08$ & $4.15 \mathrm{E}-08$ & $4.31 \mathrm{E}-09$ & $2.65 \mathrm{E}-07$ & $9.42 \mathrm{E}-08$ & $1.28 \mathrm{E}-07$ \\
\hline \multicolumn{8}{|c|}{ Probabilistic approach $(N=10,000)$} \\
\hline BDCM & $3.18 \mathrm{E}-07$ & $7.41 \mathrm{E}-06$ & $2.25 \mathrm{E}-05$ & $3.93 \mathrm{E}-14$ & $4.89 \mathrm{E}-04$ & $1.94 \mathrm{E}-05$ & $3.87 \mathrm{E}-05$ \\
\hline DBCM & $5.07 \mathrm{E}-07$ & $6.81 \mathrm{E}-06$ & $2.24 \mathrm{E}-05$ & $1.76 \mathrm{E}-13$ & $1.18 \mathrm{E}-03$ & $1.88 \mathrm{E}-05$ & $3.35 \mathrm{E}-05$ \\
\hline Bromoform & $3.71 \mathrm{E}-08$ & $1.53 \mathrm{E}-07$ & $3.10 \mathrm{E}-07$ & $3.62 \mathrm{E}-19$ & $8.60 \mathrm{E}-06$ & $4.27 \mathrm{E}-07$ & $6.99 \mathrm{E}-07$ \\
\hline Benzene & $3.34 \mathrm{E}-08$ & $4.73 \mathrm{E}-08$ & $4.81 \mathrm{E}-08$ & $1.23 \mathrm{E}-09$ & $1.09 \mathrm{E}-06$ & $9.65 \mathrm{E}-08$ & $1.34 \mathrm{E}-07$ \\
\hline
\end{tabular}

order to prevent overestimation. However, a similar conclusion could not be drawn swiftly in this study, because while in general median and mean levels estimated using deterministic approach were lower than those calculated by probabilistic approach, the opposite was true for the upper-end tail of the distributions. This is an indicator of close similarity between empirical distributions of individual exposures and risks, and the presumed population distributions.

The lifetime cancer risks for BDCM, DBCM, and bromoform reported by Hsu and co-workers (2001) for 2l/d DI were greater than the median $R$ values and less than the mean $R$ values given in Table 8. For Taiwan tap water, the acceptable risk level was exceeded for BDCM in all areas and for DBCM in two areas. In addition, Hsu et al. (2001) estimated increased cancer risks of up to 179 times the acceptable level for chloroform using a SF of $6.1 \times 10^{-3}(\mathrm{mg} / \mathrm{kg} / \mathrm{d})^{-1}$. Lee et al. (2004) estimated lifetime cancer risks through ingestion of THMs in Hong Kong tap water and stated that the values calculated for chloroform, BDCM, and DBCM were greater than $10^{-6}$ in all districts. The highest estimates were obtained for BDCM and risks as high as $6.82 \times 10^{-5}$ were reported. In this study, however, higher risks were calculated for DBCM when compared to those for BDCM. Tokmak et al. (2004) have pointed that the lifetime cancer risks associated with exposure to TTHMs found in Ankara tap water were above the acceptable risk level when all routes of exposure were taken into consideration. Although cancer risk estimates were not reported separately for the ingestion route, those should be higher than the values calculated for İmir drinking water, since (1) the concentrations of THMs found in Ankara drinking water were much greater than those found in Izmir drinking water, (2) the DI and BW constants they used were not less than those given for the individuals investigated in this study, and (3) all the population is assumed to consume tap water supplied by the municipality. In addition, referred studies employed the former SF value for chloroform that has been withdrawn which probably resulted in higher risk estimates because, generally, the most abundant THM is chloroform.
The results of Mann-Whitney and Kruskal-Wallis tests used to compare the CDI, HQ and $R$ values across subgroups were in total agreement with the $p$-values reported for VOC concentrations. Significant differences discussed in Section 3.1 for all categories were valid for exposure and risk. This indicates that the differences in exposure to VOCs were mainly due to concentration differences and that BW and average daily intake rate of drinking water did not differ significantly within categories. Statistical analyses regarding the differences in DI and BW values across subgroups also supported this inference pointing out significances only for the sex category.

\section{Conclusions}

All VOC concentrations were in attainment of drinking water standards. The data collected in this study showed that drinking water intake and BW characteristics of the Turkish people are different from the American counterparts, and that assumptions for these two variables should be avoided when possible in risk assessment to avoid under/ overestimation of population risks. Noncarcinogenic risks attributable to ingestion of VOCs in İzmir drinking water were negligible. While 95th percentile carcinogenic risks for benzene and bromoform were $<10^{-6}$, those of BDCM and DBCM exceeded this level. More exposure/risk assessment studies concerning the Turkish population are necessary to improve the drinking water regulations since the results of this study show that oral exposure to drinking water contaminants and associated risks may be higher than the acceptable levels, even if the concentrations fall below the standards. It is obvious that aggregate exposures and risks are higher, thus, inhalation and dermal exposures are needed to be quantified.

\section{Acknowledgments}

This study was supported by research grants from the Scientific and Technical Research Council of Turkey (TÜBI- 
TAK) (İCTAG Ç-077, 2003) and İzmir Institute of Technology (BAP-2003-42). However, it has not been subjected to TUBITAK's peer and policy review and therefore does not necessarily reflect the views of TUBITAK and no official endorsement should be inferred.

\section{R E F E R E N C E S}

Calderon, R.L., 2000. The epidemiology of chemical contaminants of drinking water. Food Chem. Toxicol. 38, S13-S20.

Cantor, K.P., 1997. Drinking water and cancer. Cancer Causes Control 8, 292-308.

Capar, G., Yetis, U., 2002. Removal of THM precursors by GAC: Ankara case study. Water Res. 36, 1379-1384.

Chrostowski, P.C., 1994. Exposure assessment principles. In: Patrick, D.R. (Ed.), Toxic Air Pollution Handbook. Van Nostrand Reinhold, New York, 154pp.

Clayton, C.A., Pellizzari, E.D., Whitmore, R.W., Perritt, R.L., Quackenboss, J.J., 1999. National Human Exposure Assessment Survey (NHEXAS): distributions and associations of lead, arsenic and volatile organic compounds in EPA Region 5. J. Exposure Anal. Environ. Epidemiol. 9, 381-392.

Fawell, J., 2000. Risk assessment case study-chloroform and related substances. Food Chem. Toxicol. 38, S91-S95.

Gelover, S., Bandala, E.R., Leal-Ascencio, T., Pérez, S., Martínez, E., 2000. GC-MS determination of volatile organic compounds in drinking water supplies. Environ. Toxicol. 15, 131-139.

Golfinopoulos, S.K., 2000. The occurrence of trihalomethanes in the drinking water in Greece. Chemosphere 41, 1761-1767.

Health Canada, 1998. Assessment and management of cancer risks from radiological and chemical hazards. 98-EHD-216 AECB INFO-0684(E) AC-5.

Hofer, M., Shuker, L., 2000. ILSI Europe workshop on assessing health risks from environmental exposure to chemicals: the example of drinking water, Summary report. Food Chem. Toxicol. 38, S3-S12.

Hsu, C.H., Jeng, W.L., Chang, R.M., Chien, L.C., Han, B.C., 2001. Estimation of potential lifetime cancer risks for trihalomethanes from consuming chlorinated drinking water in Taiwan. Environ. Res. Section A 85, 77-82.

IRIS, 2005. Integrated Risk Information System, US Environmental Protection Agency, Cincinnati, OH. Accessed at: 〈http:// www.epa.gov/iris $>$.

Kavcar, P., 2005. Assessment of exposure and risk associated with trihalomethanes and other volatile organic compounds in drinking water. M.Sc. Thesis, İzmir Institute of Technology, İzmir, Turkey.

Kostopoulou, M.N., Golfinopoulos, S.K., Nikolaou, A.D., Xilourgidis, N.K., Lekkas, T.D., 1999. Volatile organic compounds in the surface waters of Northern Greece. Chemosphere 40, 527-532.

Kuo, H.W., Chiang, T.F., Lo, I.I., Lai, J.S., Chan, C.C., Wang, J.D., 1997. VOC concentration in Taiwan's household drinking water. Sci. Total Environ. 208, 41-47.

Lebowitz, M.D., O’Rourke, M.K., Gordon, S., Moschandreas, D.J., Buckley, T., Nishioka, M., 1995. Population-based exposure measurements in Arizona: a phase I field study in support of the National Human Exposure Assessment Survey. J. Exposure Anal. Environ. Epidemiol. 5 (3), 297-325.

Lee, S.C., Guo, H., Lam, S.M.J., Lau, S.L.A., 2004. Multipathway risk assessment on disinfection by-products of drinking water in Hong Kong. Environ. Res. 94, 47-56.

Ministry of Health, 2005. İnsani tüketim amaçlı sular hakkında yönetmelik (Regulation concerning water intended for human consumption). Resmi Gazete: 25730, Ankara.
Patrick, D.R., 1994. Risk assessment and risk management. In: Patrick, D.R. (Ed.), Toxic Air Pollution Handbook. Van Nostrand Reinhold, New York, 347pp.

Robertson, G.L., Lebowitz, M.D., O’Rourke, M.K., Gordon, S., Moschandreas, D., 1999. The National Human Exposure Assessment Survey (NHEXAS) study in Arizona-introduction and preliminary results. J. Exposure Anal. Environ. Epidemiol. 9, 427-434.

Simpson, K.L., Hayes, K.P., 1998. Drinking water disinfection byproducts: an Australian perspective. Water Res. 32 (5), 1522-1528.

Sofuoglu, C.S., Lebowitz, M.D., O’Rourke, M.K., Robertson, G.L., Dellarco, M., Moschandreas, D.J., 2003. Exposure and risk estimates for Arizona drinking water. J. Am. Water Works Assoc. 95 (7), 67-79.

Squillace, P.J., Scott, J.C., Moran, M.J., Nolan, B.T., Kolpin, D.W., 2002. VOCs, pesticides, nitrate, and their mixtures in groundwater used for drinking water in the United States. Environ. Sci. Technol. 36, 1923-1930.

The European Communities (Drinking Water) Regulations, 2000. SI No: 439, Government Supplies Agency, Dublin.

Tokmak, B., Capar, G., Dilek, F.B., Yetis, U., 2004. Trihalomethanes and associated potential cancer risks in the water supply in Ankara, Turkey. Environ. Res. 96, 345-352.

Toroz, I., Uyak, V., 2005. Seasonal variations of trihalomethanes (THMs) in water distribution networks of Istanbul City. Desalination 176, 127-141.

USEPA (US Environmental Protection Agency), 1992a. Guidelines for Exposure Assessment. Risk Assessment Forum, Washington, DC EPA/600/Z-92/001.

USEPA, 1992b. Method 524.2, Measurement of Purgeable Organic Compounds in Water by Capillary Column Gas Chromatography/Mass Spectrometry, Revision 4.0. Environmental Monitoring Systems Laboratory, Office of Research and Development, Cincinnati, $\mathrm{OH}$.

USEPA, 1997a. Exposure Factors Handbook. Office of Research and Development National Center for Environmental Assessment, Washington, DC EPA/600/P-95/002Fa.

USEPA, 1997b. Guiding Principles for Monte Carlo Analysis. Risk Assessment Forum, Washington, DC EPA/630/R-97/001.

USEPA, 1999a. Guidelines for Carcinogen Risk Assessment. Risk Assessment Forum, Washington, DC NCEA-F-0644, Review Draft.

USEPA, 1999b. Guidance for Performing Aggregate Exposure and Risk Assessments. Office of Pesticide Programs, Washington, DC.

USEPA, 2000a. Revisions to the methodology for deriving ambient water quality criteria for the protection of human health. Accessed at: 〈http://www.epa.gov/EPAWATER/2000/ November/Day-03/w27924.htm $\rangle$.

USEPA, 2000b. Water quality standards; Establishment of numeric criteria for priority toxic pollutants for the State of California. Accessed at: 〈http://www.epa.gov/EPAWATER/2000/May/ Day-18/w11106.htm $\rangle$.

USEPA, 2002a. Code of Federal Regulations, 40CFR141.61, Title 40Protection of Environment, Chapter 1- Environmental Protection Agency, Part 141- National Primary Drinking Water Regulations, 141.61- Maximum Contaminant Levels for Organic Contaminants. Accessed at: 〈http://a257. g.akamaitech.net/7/257/2422/14mar20010800/edocket. access.gpo.gov/cfr_2002/julqtr/pdf/40cfr141.61.pdf $>$.

USEPA, 2002b. Code of Federal Regulations, 40CFR141.64, Title 40Protection of Environment, Chapter 1- Environmental Protection Agency, Part 141- National Primary Drinking Water Regulations, 141.64- Maximum Contaminant Levels for Disinfection Byproducts. Accessed at: 〈http://a257.g.akamaitech. net/7/257/2422/14mar20010800/edocket.access.gpo.gov/ cfr_2002/julqtr/pdf/40cfr141.64.pdf $>$. 
USEPA, 2004. Estimated Per Capita Water Ingestion and Body Weight in the United States-An Update. Office of Water, Washington, DC EPA-822-R-00-001.

Weisel, C.P., Kim, H., Haltmeier, P., Klotz, J.B., 1999. Exposure estimates to disinfection by-products of chlorinated drinking water. Environ. Health Perspect. 107 (2), 103-110.
WHO (World Health Organization), 2004. Guidelines for Drinkingwater Quality, third ed., vol. 1, Recommendations. World Health Organization, Geneva.

Williams, P., Benton, L., Warmerdam, J., Sheehan, P., 2002. Comparative risk analysis of six volatile organic compounds in California drinking water. Environ. Sci. Technol. 36, 4721-4728. 